\title{
Resíduos culturais e resultado de análise de solo coletado com diferentes amostradores no sistema de plantio direto
}

\author{
Crop residues and soil testing results of samples collected by using different soil \\ samplers on no-tillage system
}

\author{
Pedro Alexandre Varella Escosteguy ${ }^{1}$ Daniel Henkin ${ }^{2}$ Márcio Henkes Caldeira ${ }^{2}$ \\ Jair Pimentel ${ }^{3}$ Adriana Pezarico Arns ${ }^{4}$
}

\section{RESUMO}

Uma das características do sistema de plantio direto é o acúmulo de resíduos culturais na superfície do solo. Embora as recomendações técnicas preconizem a remoção desses resíduos antes da amostragem de solo, isso não ocorre quando a amostragem é efetuada utilizando o quadriciclo. Os resíduos culturais também podem ser misturados com a amostra de solo quando esse é amostrado com o trado manual e esses resíduos não são removidos da superfície do solo. Neste trabalho, estudou-se a influência dos resíduos culturais da superfície do solo nos resultados da análise de solo sob plantio direto. Amostraram-se solos com e sem a remoção de resíduos culturais da superfície. Esses procedimentos foram testados em solos contendo baixo e alto teor de argila, amostrados com o trado calador e o quadriciclo, após o cultivo de soja e milho. A influência dos resíduos culturais no resultado da análise de solo foi, em geral, pouco expressiva, variando com o tipo de amostrador, de resíduo e teor de argila do solo. Nas amostras coletadas com o quadriciclo, foi possível detectar diferenças no teor de matéria orgânica (MO) em função dos procedimentos de amostragem testados, entretanto, isso não ocorreu nas amostras coletadas com o calador. $\mathrm{Na}$ presença dos resíduos culturais, o teor de MO aumentou em $4 \mathrm{~g} \mathrm{~kg}^{-1}$ (solo com baixo teor de argila $e$ cultivado com soja) e em $5 \mathrm{~g} \mathrm{~kg}^{-1}$ (solo com alto teor de argila e cultivado com milho). Com exceção dos teores de MO, a presença dos resíduos culturais não interferiu na interpretação dos outros atributos analisados.

Palavras-chave: amostragem de solo, recomendação de adubação, matéria orgânica, plantio direto.

\begin{abstract}
One of the prominent features of no-till system is the accumulation of crop residues left on the soil surface. Although the technical recommendation for sampling soil for testing purpose states that the crop residues should be removed from the soil surface, it is not feasible when sampling the soil with a geo-referenced hydraulic soilcoring probe. The soil samples may also be mixed with the crop residues when they are taken without removing these residues from the soil surface, which happen frequently. The objective of this study was to evaluate the effect of removing the crop residues on soil test results. Soil sampling was carried out with and without the crop residues presence. It was carried out on sandy and clayey soils, sampled with a soil auger or a geo-referenced hydraulic soil coring probe. The effect of crop residues on soil test results was not expressive. It changed according to the type of soil sampler used, the crop residue, and the clay content. By using the hydraulic sampler, it was possible to detect differences on the organic matter (OM) content of the soil sample as a function of the sampling technique, but it did not occur by using the soil auger sampler. On the crop residues presence, the OM content increased $4 \mathrm{~g} \mathrm{~kg}^{-1}$ (sandy soils where soybean was cropped) and $5 \mathrm{~g} \mathrm{~kg}^{-1}$ (clayey soils where corn was cropped). Except for the organic matter content, the sampling techniques tested did not affect the soil test results interpretation of the other variables analyzed.
\end{abstract}

Key words: soil sampling, fertilizer recommendation, organic matter, and no-till.

\footnotetext{
${ }^{1}$ Engenheiro Agrônomo, PhD, Professor Titular da Faculdade de Agronomia e Medicina Veterinária (FAMV), Universidade de Passo Fundo (UPF), CP 611, 99001-970, Passo Fundo, RS. E-mail: escosteguy@upf.br. Autor para correspondência.

${ }^{2}$ Aluno de Graduação, FAMV, UPF.

${ }^{3}$ Engenheiro agrônomo, assessor técnico da empresa Serrana Fertilizantes, Porto Alegre, RS.

${ }^{4}$ Aluno do Mestrado em Agronomia, UPF.
} 


\section{INTRODUÇÃO}

O acúmulo expressivo de resíduos culturais na superfície do solo é uma das características do sistema de plantio direto (SPD) manejado de forma adequada. A utilização da análise de solo para a avaliação da fertilidade de áreas manejadas com esse sistema pressupõe a adoção de procedimentos adequados de amostragem do solo (COMISSÃO..., 1995).

A maioria dos trabalhos de pesquisa sobre a amostragem de solo no SPD está relacionada com o estudo da variabilidade espacial dos atributos químicos e físicos do solo. Esses trabalhos têm comprovado que no SPD há uma maior variabilidade espacial (horizontal e vertical) desses atributos em relação ao sistema convencional (ANGHINONI \& SALET, 1998; SANTOS \& VASCONCELOS, 1987; SCHLINDWEIN \& ANGHINONI, 2000), o que resulta em um maior número de subamostras na amostragem de solos no SPD.

A pá de corte tem sido recomendada para a amostragem de solos adubados no sulco de plantio desde a época em que o SPD era pouco utilizado no Sul do Brasil (COMISSÃO..., 1995). Recentemente, NICOLODI et al. (2002) comprovaram que o calador também pode ser utilizado na amostragem de solos adubados no sulco de plantio. Conforme esses autores, o uso desse amostrador nessa situação requer a amostragem de pontos localizados no sulco de plantio e localizados entre o sulco. Essa constatação contribui para o uso adequado do calador, o qual tem sido um dos amostradores mais utilizados na amostragem de solos no SPD. Quando da amostragem com o calador, os resíduos culturais não removidos da superfície do solo podem ser coletados junto com o solo amostrado, principalmente, quando esse amostrador não apresenta uma extremidade cortante e a quantidade desses resíduos é expressiva. Conforme COMISSÃO...(1995), deve-se remover os resíduos culturais da superfície do solo, antes da amostragem. No entanto, muitos produtores amostram o solo sem a remoção desses resíduos, pois acreditam que a influência desses sobre a disponibilidade de nutrientes seria mais bem estimada, o que difere dos procedimentos adotados nos estudos de correlação que embasaram as tabelas de recomendação de adubação sugeridas pela COMISSÃO...(1995). Esses resíduos também não são removidos da superfície do solo quando esse é amostrado com o quadriciclo. Embora o quadriciclo possibilite a amostragem do solo em menor intervalo de tempo do que o trado manual, esse equipamento não possui mecanismo capaz de remover os resíduos culturais da superfície do solo.
Embora sejam conhecidos os efeitos dos resíduos culturais na ciclagem e na dinâmica de nutrientes no sistema convencional de cultivo do solo (BAYER \& MIELNICZUK, 1999), pouco se sabe sobre a influência desses resíduos nos resultados da análise de solo, quando eles não são removidos da superfície de solos amostrados no SPD. Este trabalho teve como objetivo estudar a influência dos resíduos culturais, após o cultivo de milho e soja, nos resultados da análise de solo, amostrado com o trado calador e o quadriciclo.

\section{MATERIAL E MÉTODOS}

Coletaram-se amostras de quatro solos (Latossolo Vermelho distrófico típico), manejados, há mais de oito anos, no SPD. Dois desses solos contém baixo teor de argila (267 a $273 \mathrm{~g} \mathrm{~kg}^{-1}$ ) e os outros dois apresentam alto teor de argila (500 a $600 \mathrm{~g} \mathrm{~kg}^{-1}$ ). Um dos solos com baixo teor de argila foi cultivado com milho e o outro com soja, antes da amostragem. Isso também ocorreu nos solos com alto teor de argila. O cultivo de soja foi precedido de aveia e azevém (2001) e soja (2000/2001), enquanto que o cultivo de milho foi precedido de nabo forrageiro (2001), no solo com baixo teor de argila, e de centeio (2001), no solo com alto teor de argila, além de milho (2000/2001).

A amostragem dos solos foi efetuada aos 25 (soja) e 55 (milho) dias após a colheita dos grãos. As amostras de solos foram coletadas inteiramente ao acaso, na profundidade de 0 a $10 \mathrm{~cm}$ (COMISSÃO..., 1998; COMISSÃO..., 2000), em áreas de 5ha. Foram coletadas três amostras (repetições) compostas de dez subamostras, utilizando-se o trado calador e o quadriciclo. O calador é constituído por um tubo de aço inoxidável $(2,5 \mathrm{~cm}$ de diâmetro), com uma extremidade cortante, na forma de fenda lateral ao longo da profundidade amostrada $(10 \mathrm{~cm})$ e com uma outra extremidade onde há um cabo com formato em “T”. O quadriciclo é constituído por um trado de rosca, confeccionado com aço inoxidável, envolto por um cilindro metálico, sendo regulado (profundidade) e acionado (perfuração e movimento) eletricamente. $\mathrm{Na}$ área cultivada com milho, os solos amostrados com o calador foram retirados da entrelinha para evitar a influência da adubação no sulco; na área cultivada com soja, a adubação foi realizada a lanço, dispensando esse procedimento. As amostras foram coletadas (a) após a remoção manual dos resíduos culturais da superfície do solo e (b) mantendo-se os resíduos culturais na superfície do solo.

Os resíduos culturais foram coletados utilizando-se um quadro de PVC, com largura e 
comprimento de 0,50 m e diâmetro de $1,25 \mathrm{~cm}$, no mesmo dia em que os solos foram amostrados. Foram coletadas duas amostras (repetições) compostas de cinco subamostras ( $0,25 \mathrm{~m}^{2} /$ cada uma). As amostras de solos e de resíduos culturais foram analisadas de acordo com os procedimentos descritos em TEDESCO et al. (1995). O delineamento experimental foi completamente casualizado e a análise da variância do efeito dos resíduos culturais foi quantificada utilizando-se o pacote estatístico SAS (STATISTICAL ANALYSIS SYSTEM, 1985).

\section{RESULTADOS E DISCUSSÃO}

\section{Trado calador}

Nas amostras de solos contendo baixo teor de argila houve decréscimo de 0,2 unidades nos valores do índice SMP (de 5,4 para 5,2) quando os resíduos culturais da área cultivada com milho não foram removidos da superfície do solo. Essa variação foi acompanhada de um pequeno aumento nos teores de $\mathrm{H}+\mathrm{Al}$, que variaram de 9,0 para $10,5 \mathrm{cmol}_{\mathrm{c}} \mathrm{dm}^{3}$, o que resultou em um aumento da CTC (Tabela 1). Esse aumento da CTC deve-se à maior acidez potencial, que

Tabela 1 - Atributos químicos dos latossolos com baixo teor de argila, amostrados com o trado calador, após a remoção ou não dos resíduos culturais, em áreas cultivadas com milho ou soja.

\begin{tabular}{|c|c|c|c|c|}
\hline \multirow{2}{*}{ Atributo químico } & \multicolumn{2}{|c|}{$\begin{array}{l}\text { Área cultivada } \\
\text { com milho }\end{array}$} & \multicolumn{2}{|c|}{$\begin{array}{l}\text { Área cultivada } \\
\text { com soja }\end{array}$} \\
\hline & $\begin{array}{l}\text { Com } \\
\text { resíduo }\end{array}$ & $\begin{array}{l}\text { Sem } \\
\text { resíduo }\end{array}$ & $\begin{array}{l}\text { Com } \\
\text { resíduo }\end{array}$ & $\begin{array}{l}\text { Sem } \\
\text { resíduo }\end{array}$ \\
\hline $\mathrm{MO}\left(\mathrm{g} \mathrm{kg}^{-1}\right)$ & 34 & 35 & 25 & 28 \\
\hline $\mathrm{pH}\left(\mathrm{H}_{2} \mathrm{O}\right)$ & 4,8 & 4,9 & 5,5 & 5,6 \\
\hline Índice SMP & $5,2^{*}$ & $5,4^{*}$ & 6,0 & 6,0 \\
\hline P disponível (mg dm ${ }^{-3}$ ) & 11,0 & 12,3 & $37,0 *$ & $43,3 *$ \\
\hline K disponível (mg dm ${ }^{-3}$ ) & 84 & 104 & $119 *$ & $143 *$ \\
\hline $\mathrm{Al}$ trocável $\left(\mathrm{cmol}_{\mathrm{c}} \mathrm{dm}^{-3}\right)$ & 1,1 & 0,8 & 0,0 & 0,0 \\
\hline Ca trocável $\left(\mathrm{cmol}_{\mathrm{c}} \mathrm{dm}^{-3}\right)$ & 3,1 & 3,3 & 4,5 & 4,8 \\
\hline Mg trocável $\left(\mathrm{cmol}_{\mathrm{C}} \mathrm{dm}^{-3}\right)$ & 1,5 & 1,6 & 1,8 & 1,9 \\
\hline $\mathrm{H}+\mathrm{Al}\left(\mathrm{cmol}_{\mathrm{c}} \mathrm{dm}^{-3}\right)$ & $10,5^{*}$ & $9,0^{*}$ & 4,4 & 4,6 \\
\hline CTC $\left(\mathrm{cmol}_{\mathrm{c}} \mathrm{dm}^{-3}\right)$ & $15,4^{*}$ & $14,2^{*}$ & 11,0 & 11,6 \\
\hline $\mathrm{V}(\%)$ & 31,7 & 36,3 & 60,3 & 60,7 \\
\hline $\mathrm{Al} / \mathrm{CTC}(\%)$ & 18,7 & 14,0 & 0,0 & 0,0 \\
\hline K/CTC (\%) & $1,4^{*}$ & $1,9 *$ & 2,8 & 3,2 \\
\hline $\mathrm{S}$ disponível (mg dm ${ }^{-3}$ ) & 8,3 & 11,7 & 10,7 & 13,7 \\
\hline B disponível (mg dm ${ }^{-3}$ ) & 0,2 & 0,2 & 0,2 & 0,2 \\
\hline Mn trocável (mg dm-3) & 30,3 & 31,3 & 14,0 & 16,0 \\
\hline Zn extraível (mg dm ${ }^{-3}$ ) & 1,8 & 2,2 & 2,4 & 2,3 \\
\hline Cu extraível (mg dm ${ }^{-3}$ ) & 0,8 & 0,7 & 0,6 & 0,6 \\
\hline
\end{tabular}

* Médias comparadas entre si pelo F-teste. Tratamentos diferem entre si a 5\% de probabilidade, quando comparados dentro de um mesmo tipo de resíduo cultural. é estimada pelo índice SMP. O aumento da CTC resultou na diminuição da saturação do K, o qual não foi uma conseqüência direta da presença dos resíduos culturais nas amostras, mas do efeito indireto desses resíduos em alterar a acidez potencial e a CTC do solo (Tabela 1). Os demais atributos químicos analisados não variaram entre os dois procedimentos testados no solo contendo baixo teor de argila e cultivado com milho (Tabela 1).

Na presença dos resíduos culturais da área cultivada com soja, houve decréscimo dos teores de P e K disponíveis nas amostras de solos contendo baixo teor de argila. Entretanto, esse decréscimo não foi capaz de alterar a interpretação dos teores desses nutrientes, os quais são considerados altos $\left(\mathrm{P}>18,0 \mathrm{mg} \mathrm{dm}^{-3}\right.$ e $\mathrm{K}>80,0 \mathrm{mg} \mathrm{dm}^{-3}$; COMISSÃO..., 1995) nessas amostras. Essa variação dos teores de $\mathrm{P}$ e $\mathrm{K}$ disponíveis não foi verificada nas amostras contendo os resíduos culturais da área cultivada com milho (Tabela 1), embora o teor de K desses resíduos tenha sido maior do que o obtido nos resíduos culturais da área cultivada com soja e o teor de $\mathrm{P}$ nos resíduos culturais dessas duas áreas tenha sido equivalente (Tabela 2). Assim, os resultados de $\mathrm{P}$ e $\mathrm{K}$ disponíveis obtidos nas amostras de solos coletados na área cultivada com soja não condizem com os resultados obtidos na análise dos resíduos culturais dessa área. Essa contradição sugere que as diferenças de $\mathrm{P}$ e de $\mathrm{K}$ disponíveis podem estar relacionadas a um outro fator (por exemplo,

Tabela 2 - Matéria seca (MS) e teor total de nutrientes dos resíduos culturais coletados na superfície dos latossolos amostrados.

\begin{tabular}{|c|c|c|c|c|}
\hline \multirow{2}{*}{$\begin{array}{l}\text { Atributo } \\
\text { químico }\end{array}$} & \multicolumn{2}{|c|}{$\begin{array}{l}\text { Solo com baixo teor de } \\
\text { argila }\end{array}$} & \multicolumn{2}{|c|}{$\begin{array}{l}\text { Solo com alto teor de } \\
\text { argila }\end{array}$} \\
\hline & $\begin{array}{l}\text { Cultivo } \\
\text { de milho }\end{array}$ & $\begin{array}{l}\text { Cultivo de } \\
\text { soja }\end{array}$ & $\begin{array}{l}\text { Cultivo de } \\
\text { milho }\end{array}$ & $\begin{array}{l}\text { Cultivo } \\
\text { de soja }\end{array}$ \\
\hline MS (t ha $\left.{ }^{-1}\right)$ & 10,77 & 12,57 & 12,76 & 9,68 \\
\hline N (\%) & $0,75^{*}$ & $1,04 *$ & 0,92 & 0,81 \\
\hline P (\%) & 0,10 & 0,15 & 0,10 & 0,12 \\
\hline K (\%) & $0,42 *$ & $0,24 *$ & 0,21 & 0,16 \\
\hline Ca (\%) & 0,25 & 0,82 & $2,12 *$ & $0,61 *$ \\
\hline $\operatorname{Mg}(\%)$ & 0,16 & 0,19 & $0,70 *$ & $0,10 *$ \\
\hline S (\%) & 21,66 & 27,86 & 25,21 & 15,92 \\
\hline $\mathrm{Zn}\left(\mathrm{mg} \mathrm{kg}{ }^{-1}\right)$ & 17,53 & 22,21 & $23,70 *$ & $40,05^{*}$ \\
\hline $\mathrm{Cu}\left(\mathrm{mg} \mathrm{kg}^{-1}\right)$ & 8,55 & 10,92 & $26,14^{*}$ & $56,55^{*}$ \\
\hline $\operatorname{Mn}\left(\mathrm{mg} \mathrm{kg}^{-1}\right)$ & 245 & 163 & $210^{*}$ & $471 *$ \\
\hline $\mathrm{B}\left(\mathrm{mg} \mathrm{kg}^{-1}\right)$ & $97,82 *$ & $78,90 *$ & 87,76 & 96,21 \\
\hline $\mathrm{Na}\left(\mathrm{mg} \mathrm{kg}^{-1}\right)$ & 63,42 & 52,09 & 55,49 & 48,70 \\
\hline
\end{tabular}

*Médias comparadas entre si pelo F-teste. Tratamentos diferem entre si a $5 \%$ de probabilidade, quando comparados dentro de um mesmo tipo de solo. 
variabilidade espacial desses elementos no solo) e não a um efeito direto da presença dos resíduos culturais. Com exceção do $\mathrm{P}$ e do $\mathrm{K}$ disponíveis, os demais atributos químicos analisados não variaram entre os dois procedimentos testados no solo com baixo teor de argila e cultivado com soja (Tabela 1).

Entre os atributos químicos analisados nas amostras contendo alto teor de argila somente o teor de Mn e de P variaram em função dos procedimentos testados (Tabela 3). O teor desses nutrientes aumentou na presença dos resíduos culturais. Na área cultivada com milho, houve acréscimo do teor de Mn trocável, enquanto na área cultivada com soja isso ocorreu com o P (Tabela 3). Esses acréscimos dos teores de Mn trocável e de P disponível não foram suficientes para mudar a interpretação do teor de $\mathrm{P}$ ou a recomendação de calagem, utilizando os critérios sugeridos pela COMISSÃO... (1995), para várias culturas de inverno, como o trigo, gramíneas forrageiras, aveia e cevada. Os resultados obtidos na análise química dos resíduos culturais não mostram diferenças entre o teor de $\mathrm{P}$ dos resíduos coletados nas áreas cultivadas com milho e naquelas com soja (Tabela 2). Assim, o acréscimo desse

Tabela 3 - Atributos químicos dos latossolos com alto teor de argila, amostrados com o trado calador, após a remoção ou não dos resíduos culturais, em áreas cultivadas com milho ou soja.

\begin{tabular}{|c|c|c|c|c|}
\hline \multirow{2}{*}{ Atributo químico } & \multicolumn{2}{|c|}{$\begin{array}{l}\text { Área cultivada } \\
\text { com milho }\end{array}$} & \multicolumn{2}{|c|}{$\begin{array}{l}\text { Área cultivada } \\
\text { com soja }\end{array}$} \\
\hline & $\begin{array}{l}\text { Com } \\
\text { resíduo }\end{array}$ & $\begin{array}{l}\text { Sem } \\
\text { resíduo }\end{array}$ & $\begin{array}{l}\text { Com } \\
\text { resíduo }\end{array}$ & $\begin{array}{l}\text { Sem } \\
\text { resíduo }\end{array}$ \\
\hline $\mathrm{MO}\left(\mathrm{g} \mathrm{kg}^{-1}\right)$ & 40 & 40 & 35 & 33 \\
\hline $\mathrm{pH}\left(\mathrm{H}_{2} 0\right)$ & 5,8 & 5,8 & 5,4 & 5,4 \\
\hline Índice SMP & 6,1 & 6,1 & 5,8 & 5,9 \\
\hline P disponível (mg dm³) & 21,0 & 24,7 & $24,7 *$ & $19,7^{*}$ \\
\hline K disponível (mg dm³) & 189 & 201 & 194 & 195 \\
\hline Al trocável $\left(\mathrm{cmol}_{\mathrm{c}} \mathrm{dm}^{-3}\right)$ & 0,0 & 0,0 & 0,1 & 0,1 \\
\hline Ca trocável $\left(\mathrm{cmol}_{\mathrm{c}} \mathrm{dm}^{-3}\right)$ & 7,1 & 7,4 & 4,8 & 4,7 \\
\hline Mg trocável $\left(\mathrm{cmol}_{\mathrm{c}} \mathrm{dm}^{-3}\right)$ & 3,6 & 3,6 & 2,6 & 2,3 \\
\hline $\mathrm{H}+\mathrm{Al}\left(\mathrm{cmol}_{\mathrm{c}} \mathrm{dm}^{-3}\right)$ & 3,9 & 3,9 & 5,3 & 5,1 \\
\hline CTC $\left(\mathrm{cmol}_{\mathrm{C}} \mathrm{dm}^{-3}\right)$ & 15,1 & 15,4 & 13,1 & 12,6 \\
\hline V (\%) & 74,3 & 74,7 & 60,0 & 59,7 \\
\hline $\mathrm{Al} / \mathrm{CTC}(\%)$ & 0,0 & 0,0 & 1,7 & 1,0 \\
\hline K/CTC (\%) & 3,2 & 3,3 & 3,8 & 3,9 \\
\hline S disponível (mg dm $\left.{ }^{-3}\right)$ & 13,3 & 13,0 & 11,3 & 11,7 \\
\hline B disponível (mg dm $\left.{ }^{-3}\right)$ & 0,3 & 0,5 & 0,4 & 0,5 \\
\hline Mn trocável (mg dm ${ }^{-3}$ ) & $20,3^{*}$ & $14,3^{*}$ & 39,0 & 31,0 \\
\hline Zn extraível (mg dm-3) & 2,4 & 2,3 & 1,1 & 1,2 \\
\hline $\mathrm{Cu}\left(\mathrm{mg} \mathrm{dm}{ }^{-3}\right)$ & 2,9 & 2,7 & 4,6 & 4,4 \\
\hline
\end{tabular}

*Médias comparadas entre si pelo F-teste. Tratamentos diferem entre si a 5\% de probabilidade, quando comparados dentro de um mesmo tipo de resíduo cultural. nutriente nas amostras obtidas na presença dos resíduos culturais da área cultivada com soja (Tabela 3) pode não estar relacionado à presença desses resíduos. É possível que esse efeito esteja relacionado a um outro fator, como microvariação de P no solo, constatada em vários trabalhos de pesquisas, como os relatados por SANTOS E VASCONCELLOS (1987); SCHLINDWEIN E ANGHINONI (2000).

Os teores de matéria orgânica (MO) das amostras coletadas com o trado calador e na presença dos resíduos culturais das áreas cultivadas com milho ou soja não diferiram dos teores obtidos nas amostras nas quais esses resíduos foram removidos da superfície do solo (Tabelas 1 e 3). Esses resultados podem estar relacionados com a pouca quantidade de resíduos presente nas amostras de solo e ao pequeno volume de solo coletado com o trado calador.

A interpretação dos resultados obtidos nas análises de solo das amostras coletadas com o trado calador (Tabelas 1 e 3), utilizando os critérios sugeridos pela COMISSÃO... (1995), indica que a quantidade de fertilizante e calcário recomendado para várias culturas (trigo, gramíneas forrageiras, aveia e cevada) não varia em função da presença ou na ausência dos resíduos culturais da superfície do solo.

\section{Quadriciclo}

Na presença dos resíduos culturais da área cultivada com milho, houve acréscimo de 0,3 unidades nos valores do $\mathrm{pH}$ em água e de 0,2 unidades nos valores do índice SMP nas amostras de solos contendo baixo teor de argila e amostradas com o quadriciclo (Tabela 4). Esse acréscimo do $\mathrm{pH}$ foi acompanhado de decréscimos dos outros índices de acidez (Al e Mn trocáveis, $\mathrm{H}+\mathrm{Al}$, Al/CTC) e de acréscimos no teor de Mg trocável e na saturação de bases (V) (Tabela 4). Embora significativos, a magnitude desses efeitos foi pequena. Assim, houve decréscimo de $0,5 \mathrm{cmol} \mathrm{dm}^{-3}$ no teor de $\mathrm{Al}^{3+}$ trocável e de $9,0 \mathrm{mg} \mathrm{dm}^{-3}$ no de Mn trocável e de cerca de $9 \%$ da saturação do $\mathrm{Al}^{3+}$ trocável na CTC. Da mesma forma, o acréscimo na saturação de bases foi de cerca de $7 \%$ (Tabela 4). Essa pouca influência dos resíduos culturais da área cultivada com milho, possivelmente, deve-se à predominância dos restos culturais de milho entre os resíduos presentes nessa área. Os resíduos dessa cultura possuem baixa capacidade de neutralização da acidez do solo, o que se deve aos baixos teores de cátions e de carbono orgânico solúvel desses resíduos (MIYAZAWA et al., 1993). A neutralização da acidez do solo tem sido atribuída aos resíduos de adubos verdes, os quais possuem maior teor de ácidos orgânicos e de Ca e Mg do que os resíduos de milho (FRANCHINI et al., 2001). Esses resultados também podem estar 
Tabela 4 - Atributos químicos dos latossolos com baixo teor de argila, amostrados com o trado quadriciclo, após a remoção ou não dos resíduos culturais, em áreas cultivadas com milho ou soja.

\begin{tabular}{|c|c|c|c|c|}
\hline \multirow{2}{*}{ Atributo químico } & \multicolumn{2}{|c|}{$\begin{array}{l}\text { Área cultivada } \\
\text { com milho }\end{array}$} & \multicolumn{2}{|c|}{$\begin{array}{l}\text { Área cultivada } \\
\text { com soja }\end{array}$} \\
\hline & $\begin{array}{l}\text { Com } \\
\text { resíduo }\end{array}$ & $\begin{array}{l}\text { Sem } \\
\text { resíduo }\end{array}$ & $\begin{array}{l}\text { Com } \\
\text { resíduo }\end{array}$ & $\begin{array}{l}\text { Sem } \\
\text { resíduo }\end{array}$ \\
\hline $\mathrm{MO}\left(\mathrm{g} \mathrm{kg}^{-1}\right)$ & 33 & 33 & $29 *$ & $25^{*}$ \\
\hline $\mathrm{pH}\left(\mathrm{H}_{2} \mathrm{O}\right)$ & $5,0^{*}$ & $4,7^{*}$ & 5,5 & 5,6 \\
\hline Índice SMP & $5,4^{*}$ & $5,2 *$ & $5,8^{*}$ & $6,1^{*}$ \\
\hline P disponível (mg dm ${ }^{-3}$ ) & 12,0 & 11,3 & 40,7 & 36,7 \\
\hline K disponível (mg dm³ $\left.{ }^{-3}\right)$ & 83 & 85 & 129 & 104 \\
\hline $\mathrm{Al}$ trocável $\left(\mathrm{cmol}_{\mathrm{c}} \mathrm{dm}^{-3}\right)$ & $1,0^{*}$ & $1,5^{*}$ & 0,0 & 0,0 \\
\hline Ca trocável $\left(\mathrm{cmol}_{\mathrm{C}} \mathrm{dm}^{-3}\right)$ & 3,1 & 2,9 & 5,2 & 5,0 \\
\hline Mg trocável $\left(\mathrm{cmol}_{\mathrm{c}} \mathrm{dm}^{-3}\right)$ & $1,4^{*}$ & $1,2^{*}$ & 1,8 & 2,0 \\
\hline $\mathrm{H}+\mathrm{Al}\left(\mathrm{cmol}_{\mathrm{c}} \mathrm{dm}^{-3}\right)$ & $8,7^{*}$ & $10,5^{*}$ & $5,3^{*}$ & $4,1^{*}$ \\
\hline CTC $\left(\mathrm{cmol}_{\mathrm{C}} \mathrm{dm}^{-3}\right)$ & 13,5 & 14,9 & 12,6 & 11,3 \\
\hline V (\%) & $35,5^{*}$ & $29,0 *$ & $58,0 *$ & $64,3^{*}$ \\
\hline $\mathrm{Al} / \mathrm{CTC}(\%)$ & $17,0 *$ & $25,7^{*}$ & 0,0 & 0,0 \\
\hline K/CTC (\%) & 1,7 & 1,5 & 2,6 & 2,4 \\
\hline $\mathrm{S}$ disponível (mg dm $\left.{ }^{-3}\right)$ & 9,5 & 11,3 & 8,3 & 7,0 \\
\hline B disponível (mg dm ${ }^{-3}$ ) & 0,2 & 0,3 & 0,2 & 0,3 \\
\hline Mn trocável (mg dm $\left.{ }^{-3}\right)$ & $25,0 *$ & $34,0^{*}$ & 19,3 & 13,3 \\
\hline Zn extraível (mg dm $\left.{ }^{-3}\right)$ & 1,6 & 1,6 & $3,6^{*}$ & $1,9 *$ \\
\hline Cu extraível $\left(\mathrm{mg} \mathrm{dm}^{-3}\right)$ & 0,9 & 1,0 & $0,8^{*}$ & $0,5 *$ \\
\hline
\end{tabular}

* Médias comparadas entre si pelo F-teste. Tratamentos diferem entre si a $5 \%$ de probabilidade, quando comparados dentro de um mesmo tipo de resíduo cultural.

relacionados com o estágio de decomposição dos resíduos, já que a amostragem do solo foi efetuada 55 dias após a colheita do milho.

Ao contrário do obtido na presença dos resíduos culturais da área cultivada com milho, na presença dos resíduos culturais da área cultivada com soja, houve decréscimo do valor do índice SMP (de 6,1 para 5,8), acréscimo do teor de $\mathrm{H}+\mathrm{Al}$ (de 4,1 para $5,3 \mathrm{cmol}_{\mathrm{c}} \mathrm{dm}^{-3}$ ) e decréscimo de $6 \%$ na saturação de bases (Tabela 4). Esse último decréscimo está relacionado ao maior valor da CTC e dos teores de K obtidos na presença dos resíduos culturais, não tendo relação com os teores de $\mathrm{Ca}$ e $\mathrm{Mg}$, cujos valores variaram muito pouco entre os tratamentos testados (Tabela 4). Na presença dos resíduos culturais da área cultivada com soja, verificou-se também acréscimo dos teores de $\mathrm{Zn}$ e $\mathrm{Cu}$ nas amostras com baixo teor de argila e coletadas com o quadriciclo (Tabela 4). Embora os valores dessas variáveis tenham quase dobrado, esse acréscimo não mudou a interpretação desses nutrientes, cujas concentrações são consideradas altas (respectivamente, $>0,5$ e $>0,4 \mathrm{mg} \mathrm{dm}^{-3}$; COMISSÃO..., 1995) inclusive nas amostras obtidas na ausência dos resíduos culturais. Assim como o constatado na presença dos resíduos da área cultivada com milho, houve pequena magnitude de variação dos valores de pH e da acidez potencial na presença dos resíduos culturais da área cultivada com soja (Tabela 4).

Os resultados da análise dos solos contendo baixo teor de argila mostram que houve um pequeno acréscimo $\left(4 \mathrm{~g} \mathrm{~kg}^{-1}\right)$ no teor de $\mathrm{MO}$, quando as amostras foram obtidas na presença dos resíduos culturais na área cultivada com soja (Tabela 4). Entretanto, esse acréscimo foi suficiente para alterar a interpretação do teor de MO do solo e, assim, reduzir a quantidade de $\mathrm{N}$ recomendada para diversas culturas de inverno. Considerando o teor de MO (25 $\mathrm{kg}^{-1}$, Tabela 4) da amostra obtida na ausência dos resíduos culturais da área cultivada com soja, as quantidades de $\mathrm{N}\left(\mathrm{kg} \mathrm{ha}^{-1}\right)$ sugeridas pela COMISSÃO...(1995) são: 30 a 40 (trigo, expectativa de rendimento $>2 \mathrm{t} \mathrm{ha}^{-1}$ ), 20 (cevada), 40 a 50 (gramíneas forrageiras de estação fria) e 20 (aveia) maiores do que as recomendadas para a amostra obtida na presença dos resíduos culturais, onde obteve-se $29 \mathrm{~g} \mathrm{~kg}^{-1}$ de MO (Tabela 4). Essas diferenças na quantidade recomendada de $\mathrm{N}$ têm que ser interpretada com cautela, pois o teor de $\mathrm{MO}$ obtido na ausência dos resíduos $\left(25 \mathrm{~g} \mathrm{~kg}^{-1}\right)$ coincidiu com o valor que estabelece a faixa de interpretação de MO (= $25 \mathrm{~g} \mathrm{~kg}^{-1}$ ) da tabela de adubação nitrogenada sugerida para essas culturas.

O acréscimo de MO verificado na presença dos resíduos culturais da área cultivada com soja não ocorreu na presença dos resíduos culturais da área cultivada com milho (Tabela 4). Isso pode estar relacionado à menor quantidade de resíduos culturais na área cultivada com milho (Tabela 2), o que se deve, possivelmente, à menor concentração de $\mathrm{P}, \mathrm{K}, \mathrm{Al}$, Ca e $\mathrm{V}$ verificada no solo dessa área (Tabela 4) e ao período de tempo compreendido entre a data de colheita e a data da amostragem do solo, o qual abrangeu 25 dias na cultura da soja e 55 dias na do milho. Assim, uma fração significativa dos resíduos culturais da área cultivada com milho pode ter sido decomposta antes do solo ter sido amostrado.

No solo contendo alto teor de argila, houve um acréscimo de $5 \mathrm{~g} \mathrm{~kg}^{-1}$ no teor de $\mathrm{MO}$, quando as amostras foram coletadas na presença dos resíduos culturais da área cultivada com milho (Tabela 5), na qual foi verificada maior quantidade de resíduos culturais $\left(12,76 \mathrm{t} \mathrm{ha}^{-1}\right)$ em relação à área cultivada com soja $\left(9,68 t\right.$ ha $\left.^{-1}\right)$ (Tabela 2). Como discutido anteriormente, o acréscimo de MO nas amostras de solo pode resultar em uma redução na quantidade de 
Tabela 5 - Atributos químicos dos latossolos com alto teor de argila, amostrados com o quadriciclo, após a remoção ou não dos resíduos culturais, em áreas cultivadas com milho ou soja.

\begin{tabular}{|c|c|c|c|c|}
\hline \multirow{2}{*}{ Atributo químico } & \multicolumn{2}{|c|}{$\begin{array}{l}\text { Área cultivada } \\
\text { com milho }\end{array}$} & \multicolumn{2}{|c|}{$\begin{array}{l}\text { Área cultivada } \\
\text { com soja }\end{array}$} \\
\hline & $\begin{array}{l}\text { Com } \\
\text { resíduo }\end{array}$ & $\begin{array}{l}\text { Sem } \\
\text { resíduo }\end{array}$ & $\begin{array}{l}\text { Com } \\
\text { resíduo }\end{array}$ & $\begin{array}{l}\text { Sem } \\
\text { resíduo }\end{array}$ \\
\hline$\overline{\mathrm{MO}\left(\mathrm{g} \mathrm{kg}^{-1}\right)}$ & $40^{*}$ & $35 *$ & 34 & 33 \\
\hline $\mathrm{pH}\left(\mathrm{H}_{2} \mathrm{O}\right)$ & 5,6 & 5,6 & 5,4 & 5,3 \\
\hline Índice SMP & 6,0 & 6,0 & 5,9 & 5,8 \\
\hline P disponível (mg dm-3) & 19,3 & 20,7 & 22,7 & 20,3 \\
\hline K disponível (mg dm³) & 168 & 160 & $174 *$ & $198 *$ \\
\hline Al trocável $\left(\mathrm{cmol}_{\mathrm{c}} \mathrm{dm}^{-3}\right)$ & 0,0 & 0,0 & 0,1 & 0,2 \\
\hline Ca trocável $\left(\mathrm{cmol}_{\mathrm{c}} \mathrm{dm}^{-3}\right)$ & 6,4 & 6,1 & 5,0 & 4,9 \\
\hline Mg trocável $\left(\mathrm{cmol}_{\mathrm{c}} \mathrm{dm}^{-3}\right)$ & 3,2 & 3,1 & 2,8 & 2,6 \\
\hline $\mathrm{H}+\mathrm{Al}\left(\mathrm{cmol}_{\mathrm{c}} \mathrm{dm}^{-3}\right)$ & 4,6 & 4,6 & 4,9 & 5,3 \\
\hline CTC $\left(\mathrm{cmol}_{\mathrm{C}} \mathrm{dm}^{-3}\right)$ & 14,5 & 14,2 & 13,1 & 13,3 \\
\hline V (\%) & 68,7 & 68,0 & 62,3 & 60,0 \\
\hline $\mathrm{Al} / \mathrm{CTC}(\%)$ & 0,0 & 0,0 & 1,3 & 2,3 \\
\hline K/CTC (\%) & 3,0 & 2,9 & $3,4^{*}$ & $3,8^{*}$ \\
\hline $\mathrm{S}$ disponível (mg dm-3) & 17,3 & 9,7 & 7,3 & 12,7 \\
\hline B disponível (mg dm³) & 0,5 & 0,3 & 0,5 & 0,4 \\
\hline Mn trocável (mg dm ${ }^{-3}$ ) & 15,7 & 19,7 & 33,0 & 38,0 \\
\hline Zn extraível (mg dm ${ }^{-3}$ ) & 3,0 & 2,7 & 1,5 & 1,4 \\
\hline Cu extraível (mg dm ${ }^{-3}$ ) & 3,5 & 3,9 & 4,5 & 4,7 \\
\hline
\end{tabular}

*Médias comparadas entre si pelo F-teste. Tratamentos diferem entre si a $5 \%$ de probabilidade, quando comparados dentro de um mesmo tipo de resíduo cultural.

N recomendada, principalmente, quando da adubação das culturas cujas classes de interpretação da MO do solo estão distribuídas em faixas que apresentam intervalos pequenos de variação (trigo, cevada e gramíneas forrageiras).

A presença dos resíduos culturais da área cultivada com milho não influenciou os resultados obtidos na análise dos outros atributos químicos avaliados (Tabela 5), o que se deve ao baixo teor de nutrientes desses resíduos (Tabela 2). Por outro lado, na presença dos resíduos culturais da área cultivada com soja houve um pequeno decréscimo do teor de K disponível e, conseqüentemente, da sua saturação na CTC (Tabela 5). Entretanto, isso não altera a interpretação e a recomendação de adubação das culturas de inverno, pois os teores de $\mathrm{K}$ disponível nessas amostras são considerados altos (> 80mg $\mathrm{dm}^{-3}$; COMISSÃO..., 1995).

Ao contrário do observado no solo com baixo teor de argila (Tabela 4), nas amostras contendo alto teor de argila os valores dos índices de acidez (pH, índice SMP, V, Al/CTC, Al e Mn trocáveis) (Tabela 5) não variaram em função da presença dos resíduos culturais. Isso deve estar relacionado aos maiores teores de argila e de matéria orgânica (Tabela 5) e, conseqüentemente, ao maior poder tampão dessas amostras.

\section{CONCLUSÕES}

A influência dos resíduos culturais nos resultados da análise de solo foi, em geral, pouco expressiva. Essa influência pode variar com o tipo de resíduo cultural e o teor de argila das amostras e o tipo de amostrador. Nas amostras coletadas com o quadriciclo, o teor de matéria orgânica aumentou na presença dos resíduos culturais na área com baixo teor de argila e cultivada com soja e na área com alto teor de argila e cultivada com milho. Esse acréscimo interfere na interpretação da matéria orgânica e na recomendação da adubação nitrogenada das culturas de inverno. Nas amostras coletadas com o calador, não houve variação do teor de matéria orgânica em função da presença dos resíduos culturais. Nas amostras coletadas com ambos os amostradores estudados, a influência dos resíduos culturais não interferiu na interpretação dos outros atributos analisados (pH, índice SMP, K, P, Al, Ca, Mg, S, B, $\mathrm{Mn}, \mathrm{Zn}$ e $\mathrm{Cu})$.

\section{REFERÊNCIAS BIBLIOGRÁFICAS}

ANGHINONI, I.; SALET, R.L. Amostragem do solo e as recomendações de adubação e calagem no sistema plantio direto. In: NUERnBERG, N.J. (ed.). Conceitos e fundamentos do sistema de plantio direto. Lages : Sociedade Brasileira de Ciência do Solo, 1998. p.27-52.

BAYER, C.; MIELNICZUK, J. Conteúdo de nitrogênio total num solo submetido a diferentes métodos de preparo e sistemas de cultura. Revista Brasileira de Ciência do Solo, Viçosa, v.21, p.235-239, 1999.

COMISSÃO BRASILEIRA DE PESQUISA DE AVEIA. Recomendações técnicas para a cultura da aveia. Porto Alegre : Faculdade de Agronomia/UFRGS, 2000. 69p.

COMISSÃO DE FERTILIDADE DO SOLO RS. Recomendação de adubação e calagem para os estados do Rio Grande do Sul e de Santa Catarina. 4.ed. Passo Fundo : SBCS-Núcleo Regional Sul, 1995. 224p.

COMISSÃO SUL-BRASILEIRA DE PESQUISA DE TRIGO. Recomendações da Comissão Sul-Brasileira de Pesquisa de Trigo - 1998. Chapecó : EPAGRI, 1998. 82p.

FRANCHINI, J.C. et al. A Rapid transformation of plant water-soluble organic compounds in relation to cation mobilization in an acid Oxisol. Plant and Soil, The Netherlands, v.231, n.1, p.55-63, 2001. 
MIYAZAWA, M. et al. Efeito de material vegetal na acidez do solo. Revista Brasileira de Ciência do Solo, Campinas, v.17, p.411-416, 1993

NICOLODI, M. et al. Alternativa à coleta de uma secção transversal , com pá de corte, na largura da entrelinha, na amostragem do solo em lavouras com adubação em linha no sistema plantio direto. Revista Plantio Direto, Passo Fundo, v.3, n.69, p.22-28, 2002.

SANTOS, H.L. dos; VASCONCELOS, C.A. Determinação do número de amostras do solo para análise química em diferentes condições de manejo. Revista Brasileira de Ciência do Solo, Campinas, v.11, p.97-100, 1987.
SAS Institute. SAS User's guide; statistics. 5.ed. Cary, N.C., 1985. 956p.

SCHLINDWEIN, J.A.; ANGHINONI, I. Variabilidade horizontal de atributos de fertilidade e amostragem do solo no sistema plantio direto. Revista Brasileira de Ciência do Solo, Viçosa, v.24, p.8591, 2000.

TEDESCO, M.J. et al. Análises de solo, plantas e outros materiais. 2.ed. Porto Alegre : Universidade Federal do Rio Grande do Sul, Faculdade de Agronomia, 1995. 174p. (Boletim técnico, 5). 